12,13

\title{
Электронная структура азотсодержащих углеродных нанотрубок, облученных ионами аргона: исследование методами РФЭС и XANES
}

\author{
() С.Н. Несов ${ }^{1}$, П.М. Корусенко ${ }^{1}$, В.В. Болотов ${ }^{1}$, С.Н. Поворознюк ${ }^{1,2}$, Д.А. Смирнов ${ }^{3,4}$ \\ ${ }^{1}$ Омский научный центр СО РАН, \\ Омск, Россия \\ ${ }^{2}$ Омский государственный технический университет, \\ Омск, Россия \\ ${ }^{3}$ Санкт-Петербургский государственный университет, \\ Санкт-Петербург, Россия \\ ${ }^{4}$ Institute of Solid State Physics, Dresden University of Technology, \\ Dresden, Germany \\ E-mail: nesov@obisp.oscsbras.ru
}

(Поступила в Редакцию 11 апреля 2017 г.)

\begin{abstract}
Методами рентгеновской фотоэлектронной спектроскопии (РФЭС) и анализа ближней тонкой структуры поглощения (XANES) с использованием синхротронного излучения получены данные об изменении электронной структуры и химического состава азотсодержащих многостенных углеродных нанотрубок (N-MУНТ) вследствие облучения ионами аргона с энергией $5 \mathrm{keV}$. Установлено, что облучение приводит к увеличению степени дефектности структуры N-MУНТ и окислению углерода с образованием различных кислородсодержащих групп $\left(\mathrm{C}-\mathrm{OH}, \mathrm{C}=\mathrm{O} / \mathrm{COOH}, \mathrm{C}-\mathrm{O}-\mathrm{C} / \mathrm{O}-\mathrm{C}-\mathrm{O}, \mathrm{CO}_{3}\right)$. Наличие углерод-кислородных связей на поверхности углеродных нанотрубок связано с формированием радиационных дефектов. Показано, что увеличение в результате облучения доли атомов азота в замещающей конфигурации в структуре стенок N-МУНТ, не приводит к повышению плотности занятых состояний вблизи уровня Ферми на фоне увеличения степени дефектности структуры, окисления углерода и понижения общей концентрации азота. Полученные результаты показывают, что облучение N-MУНТ ионами аргона позволяет эффективно функционализировать их поверхность.
\end{abstract}

Исследование выполнено при частичной финансовой поддержке РФФИ в рамках научных проектов № 15-42-04308 р_сибирь_а и № 16-08-00763 а.

DOI: 10.21883/FTT.2017.10.44972.126

\section{1. Введение}

Углеродные нанотрубки (УНТ) являются предметом интенсивного исследования, поскольку обладают уникальными электрофизическими и механическими характеристиками [1]. Функционализация поверхности УНТ является необходимой процедурой при создании материалов с улучшенными поверхностными и объемными свойствами [2,3]. Для этих целей зачастую применяют химические методы, основанные на присоединении к поверхности УНТ различных кислородсодержащих групп, с использованием окислителей $\left(\mathrm{HCl}, \mathrm{H}_{2} \mathrm{SO}_{4}\right.$, $\mathrm{HNO}_{3}$ ) [4,5]. Основным недостатком указанных методов является применение опасных и токсичных реагентов, а также необходимость проведения процедур очистки функционализированных УНТ от их остатков. Другим подходом для функционализации поверхности УНТ является использование физических методов, основанные на воздействии пучков заряженных частиц [6-8]. Такие методы являются более контролируемыми и технологичными.

В настоящей работе с применением методов РФЭС и XANES проведен анализ электронной структуры азотсодержащих многостенных УНТ (N-MУНТ), облученных ионами $\mathrm{Ar}^{+}$с энергией $5 \mathrm{keV}$. Исследованы изменения химического состояния углерода и азота в стенках облученных N-MУНТ, а также плотности состояний вблизи уровня Ферми вследствие ионного облучения.

\section{2. Эксперимент}

Слои N-MУНТ были синтезированы методом CVD (Chemical Vapor Deposition) на подложках $\mathrm{Si} / \mathrm{SiO}_{2}$ при пиролизе смеси ацетонитрила с ферроценом $(100: 1)$ при температуре $800^{\circ} \mathrm{C}$. Синтезированные слои N-MУНТ были облучены ионами аргона с энергией $5 \mathrm{keV}$. Доза облучения составляла $\sim 10^{16} \mathrm{ion} / \mathrm{cm}^{2}$.

Анализ электронной структуры и химического состояния атомов углерода и азота был осуществлен с использованием методов РФЭС и XANES на оборудовании станции RGL синхротронного накопителя BESSY II (Берлин, Германия). Обзорные РФЭ-спектры регистрировались при энергии фотонов $850 \mathrm{eV}$. РФЭ-спектры остовных линий углерода и азота были измерены при энергии возбуждающих фотонов 400 и $500 \mathrm{eV}$ соответственно. При измерении спектров валентной зоны использовались фотоны с энергией $125 \mathrm{eV}$. Согласно расчетам Tanuma и др. [9] глубина выхода фотоэлектронов с уровней $\mathrm{C} 1 s$ и $\mathrm{N} 1 s$ при возбуждении с указанными энергиями составляет не более $2 \mathrm{~nm}$. 
XANES-спектры C-K края поглощения углерода регистрировались в режиме измерения тока утечки при энергетическом разрешении монохроматора не хуже $\sim 0.1 \mathrm{eV}$. Для нормировки XANES-спектров применялась процедура деления регистрируемого сигнала на ток, измеренный с пластинки чистого золота. Глубина анализа данным методом составляла $\sim 10 \mathrm{~nm}$ [10]. Измерения РФЭС и XANES-спектров проводились в сверхвысоком вакууме при давлении остаточных газов в измерительной камере $\sim 10^{-10}$ Torr.

\section{3. Результаты и их обсуждение}

На рис. 1 приведены обзорные РФЭ-спектры исходного и облученного аргоном массивов N-MУНТ, измеренные в широком диапазоне энергий связи $(650-0 \mathrm{eV})$. В спектрах наблюдаются фотоэлектронные линии кислорода $\mathrm{O} 1 s$ (энергия связи $\sim 533 \mathrm{eV}$ ), углерода С $1 s$ (энергия связи $\sim 285 \mathrm{eV}$ ) и азота $\mathrm{N} 1 s$ (энергия связи $\sim 401 \mathrm{eV}$ ), а также линии Оже-переходов C KLL (энергия связи $\sim 590 \mathrm{eV})$ О KLL (энергия связи $\sim 343 \mathrm{eV}$ ). Видно, что в спектре облученного массива N-MУНТ наблюдается значительное увеличение интенсивности кислородных линий (рис. 1, кривая 2). Результаты количественного анализа, проведенного по данным спектрам, показывают, что после облучения содержание кислорода на поверхности N-МУНТ увеличивается с 2 до 10 at.\% (таблица). При этом концентрация углерода и азота несколько снижается. Высокое содержание кислорода, по-видимому, связано с формированием структурных дефектов в стенках N-МУНТ в результате облучения с их последующим окислением на воздухе [11].

Детальный анализ изменения электронной структуры и химического состояния углерода и азота в исходных и облученных N-МУНТ был проведен по спектрам остовных линий С $1 s$ и $\mathrm{N} 1 s$.

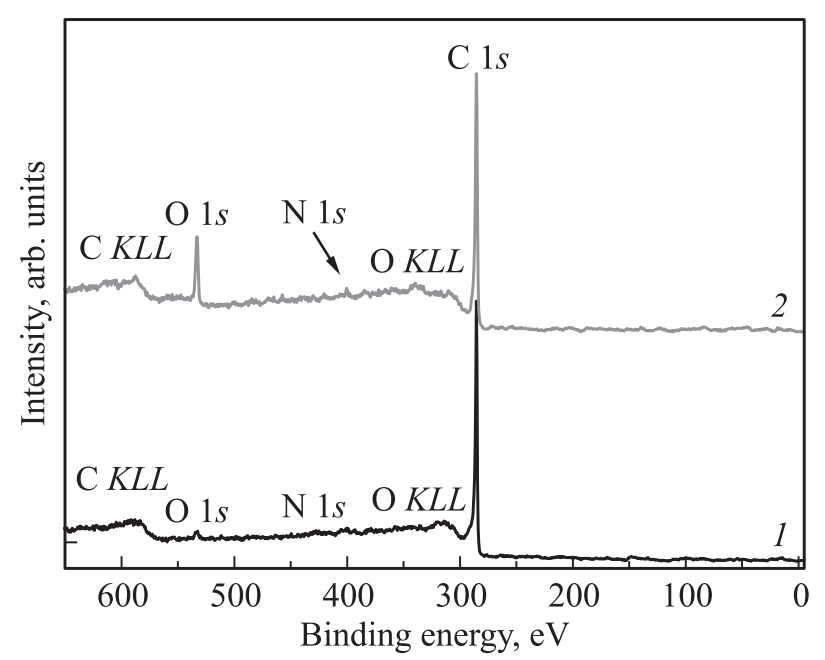

Рис. 1. Обзорные РФЭ-спектры исходных (1) и облученных N-MУHT (2).
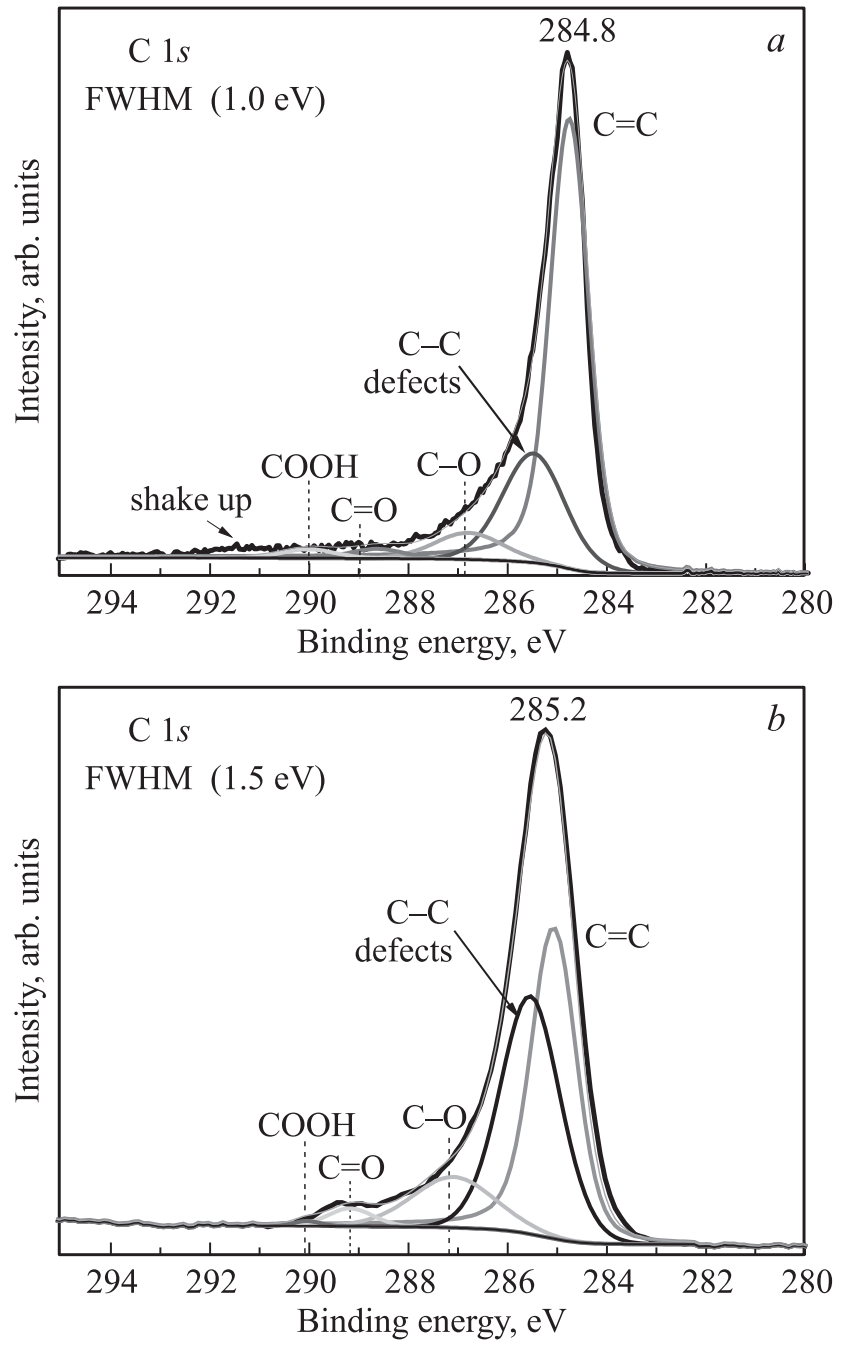

Рис. 2. РФЭ-спектры углерода (C $1 s)$ исходных $(a)$ и облученных N-МУНТ $(b)$.

На рис. 2 приведены РФЭ-спектры линий углерода (C $1 s)$ исходного и облученного N-МУНТ с разложением на компоненты. Наиболее интенсивный компонент углеродного спектра исходных N-MУНТ (рис. 2,a) с максимумом на энергии связи $284.8 \mathrm{eV}$ соответствует углероду в составе $\mathrm{C}=\mathrm{C}$ связей $\left(s p^{2}\right)$. Компонент с максимумом на энергии связи $285.4 \mathrm{eV}$ связан с наличием структурных дефектов в стенках N-MУНТ (аморфный углерод, межслоевые атомы, углерод в С-C связях

Результаты количественного РФЭС-анализа концентрации элементов и спектральные характеристики линии С $1 s$ для исходных и облученных N-МУНТ

\begin{tabular}{c|c|c|c|c|c}
\hline \multirow{2}{*}{$\begin{array}{c}\text { Режим } \\
\text { обработки }\end{array}$} & \multicolumn{2}{|c|}{ Концентрация at.\% } & \multicolumn{2}{c}{ C 1s } \\
\cline { 2 - 6 } & {$[\mathrm{C}]$} & {$[\mathrm{O}]$} & {$[\mathrm{N}]$} & Position,eV & FWHM, eV \\
\hline Исходный & 96.5 & 1.3 & 2.2 & 284.8 & 1.0 \\
Облученный & 88.8 & 9.7 & 1.5 & 285.2 & 1.5
\end{tabular}



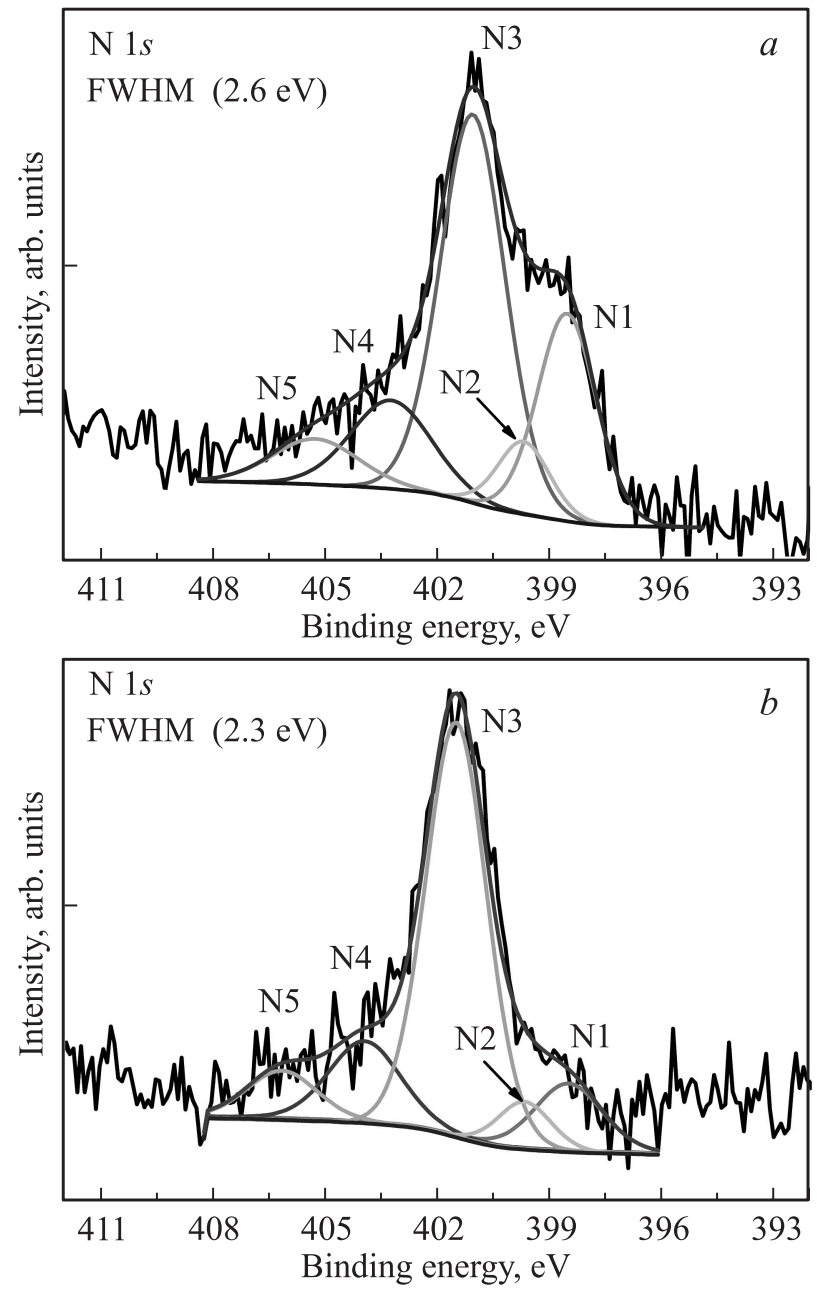

Рис. 3. РФЭ-спектры азота (N $1 s)$ исходных $(a)$ и облученных N-MУНT $(b)$.

$\left(s p^{3}\right)$ и др.). Компоненты спектра с максимумами на энергиях связи $\sim 287,289,290 \mathrm{eV}$ отвечают углероду в составе эпоксидных и фенольных групп (C-O, $\mathrm{C}-\mathrm{O}-\mathrm{C}, \mathrm{C}-\mathrm{OH})$, карбонильных групп $(\mathrm{C}=\mathrm{O})$, а также карбоксильных групп $(\mathrm{COOH})$, соответственно $[12,13]$. Наиболее высокоэнергетический компонент спектра с максимумом на энергии связи $\sim 292 \mathrm{eV}$ соответствует „shake up“ сателлиту, характерному для упорядоченных графитизированных углеродных материалов [14].

Как видно (рис. 2,b), в спектре С $1 s$ облученных N-MУНТ наблюдается значительное увеличение полуширины линии и отсутствие „shake up“ сателлита, что указывает на значительное изменение структуры и химического состояния углерода. Результаты разложения линии показывают увеличением интенсивности компонентов спектра C $1 s$ с максимумами на энергиях связи $\sim 285$ и $\sim 287, \sim 289 \mathrm{eV}$, отвечающих структурным дефектам и углерод-кислородным химическим связям соответственно. Кроме того, положение основного максимума линии С $1 s$ сдвигается в область высоких энергий связи на значение $285.2 \mathrm{eV}$, что, вероятно, связано с формированием $p$-типа дефектов на поверхности N-МУНТ в результате облучения [15]. Согласно работам [16,17] максимальный положительный сдвиг линии С $1 s$ наблюдается при формировании кислород-углеродных групп, закрепленных на вакансионных дефектах.

На рис. 3 приведены РФЭ-спектры линий азота (N $1 s)$ исходного и облученного N-МУНТ с разложением на компоненты. В спектре исходного массива (рис. 3,a) наблюдаются компоненты на энергиях связи $\sim 398 \mathrm{eV}$ $(\mathrm{N} 1), \sim 400 \mathrm{eV}(\mathrm{N} 2), \sim 401 \mathrm{eV}(\mathrm{N} 3), \sim 404 \mathrm{eV}(\mathrm{N} 4)$, $\sim 405 \mathrm{eV}$ (N5), отвечающих азоту в различных химических состояниях. Компоненты N1-N4 соответствуют азоту, встроенному в структуру стенок N-MУНТ в пиридиновой (N1), пирольной (N2), замещающей 3-х координированной (N3) конфигурациях, а также окисленному азоту (N4). Компонент N5 отвечает молекулярному азоту, присутствующему в межстеночном пространстве и полостях N-МУНТ [18,19]. Как видно (рис. 3,b), в спектре $\mathrm{N}$ 1s облученных углеродных нанотрубок наблюдается значительное уменьшение интенсивности компонента N1 и рост интенсивности компонента N3. Это свидетельствует о том, что в стенках облученных N-МУНТ основная часть азота находится в замещающей конфигурации. Как было показано в $[19,20]$ 3-х координированный азот в структуре N-MУНТ является наиболее устойчивым при термических и ионных обработках. Известно [21], что замещающий азот в структуре $s p^{2}$-углерода имеет наиболее выраженный легирующий эффект среди различных типов примесей. Следовательно, увеличение количества азота в замещающей конфигурации должно приводить к росту количества свободных носителей заряда в облученных N-МУНТ.

Для исследования изменения плотности занятых состояний вблизи уровня Ферми был проведен анализ РФЭ-спектров валентной зоны исходных и облученных N-МУНТ (рис. 4). В РФЭ-спектре валентной зоны

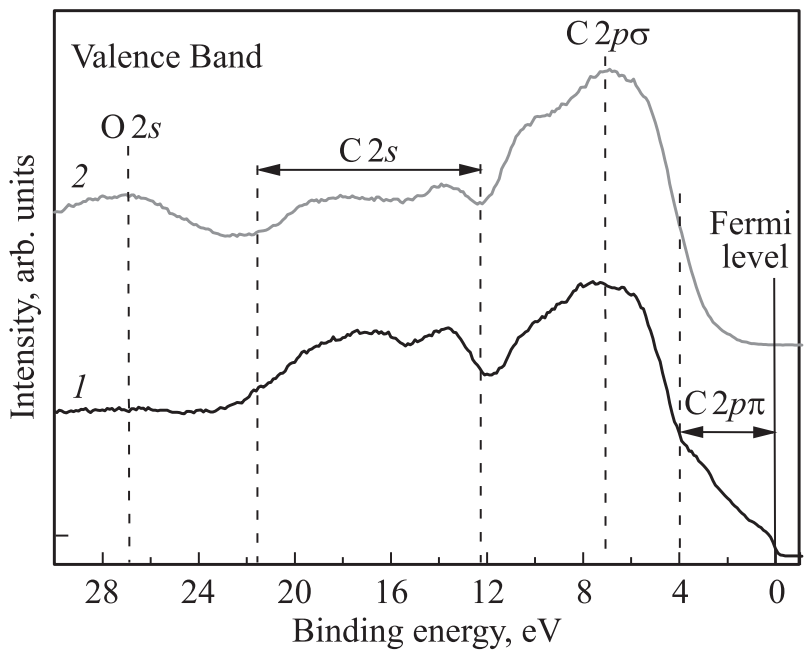

Рис. 4. РФЭ-спектры валентной зоны исходных (1) и облученных N-МУНТ (2). 
исходных углеродных нанотрубок наблюдаются спектральные особенности на энергиях $\sim 19 \mathrm{eV}$ и $\sim 13 \mathrm{eV}$, которые отвечают С $2 s$-состояниям углерода (рис. 4, кривая 1) [22,23]. Основной максимум спектра валентной зоны исходных N-MУНТ в диапазоне энергий связи $\sim 10-0 \mathrm{eV}$ сформирован гибридизированными $\mathrm{C}$ $2 p$-состояниями углерода $[22,24]$. При этом на энергиях связи от 10 до $4 \mathrm{eV}$ расположены С $2 p \sigma$-состояния углерода, а в диапазоне энергий связи от 4 до $0 \mathrm{eV}-$ С $2 p \pi$-состояния углерода [22-24]. Наличие интенсивной особенности, отвечающей С $2 p \pi$-состояниям в спектре валентной зоны исходных N-МУНТ свидетельствует о высокой степени кристалличности структуры стенок углеродных нанотрубок. Кроме того, вклад в интенсивность данной спектральной особенности вносят также дополнительные $\pi$-электроны электрически активных азотных дефектов (в замещающей и пиридиновой конфигурации). В спектре валентной зоны облученных N-MУНТ (рис. 4, кривая 2) наблюдается наличие максимума на энергиях связи $\sim 26 \mathrm{eV}$, отвечающего O 2s-состояниям кислорода [23]. В диапазоне энергий связи $\sim 12-20 \mathrm{eV}$ наблюдается снижение интенсивности и тонкой структуры спектра. Кроме того, в низкоэнергетической области спектра вблизи уровня Ферми отсутствует особенность, отвечающая С $2 p$-состояниям. Указанные изменения, наблюдаемые в спектре валентной зоны облученных углеродных нанотрубок, свидетельствуют о повышении дефектности стенок N-МУНТ, их окислении и снижении концентрации свободных электронов. Облучение ионами аргона создает радиационные дефекты, приводящие к разрушению системы $\pi$-электронов $s p^{2}$-углерода [25]. При этом, появление 2- $x$ координированных атомов углерода в составе вакансионных дефектов, которые обладают высокой реакционной способностью [26], приводит к закреплению кислорода к стенкам N-MУНТ в виде различных функциональных групп. В результате этого снижается количество свободных носителей заряда на поверхности углеродных нанотрубок. Следовательно, увеличение количества электрически активной формы азота в замещающей конфигурации (как было показано выше), на фоне увеличения дефектности, окисления углерода и понижения общей концентрации азота, повидимому, незначительно влияет на концентрацию свободных электронов.

Дополнительный анализ структуры, химического состояния углерода и кислородсодержащих функциональных групп, присутствующих на поверхности облученных N-МУНТ, и влияющих на их электронную структуру был осуществлен с использованием метода XANES из спектров К-края поглощения углерода. Данный метод позволяет исследовать свободные состояния в зоне проводимости материала и является более чувствительным к изменению химического состояния поверхностных атомов углерода, чем метод РФЭС.

На рис. 5 представлены XANES-спектры К-края углерода исходных и облученных N-МУНТ. Спектр погло-

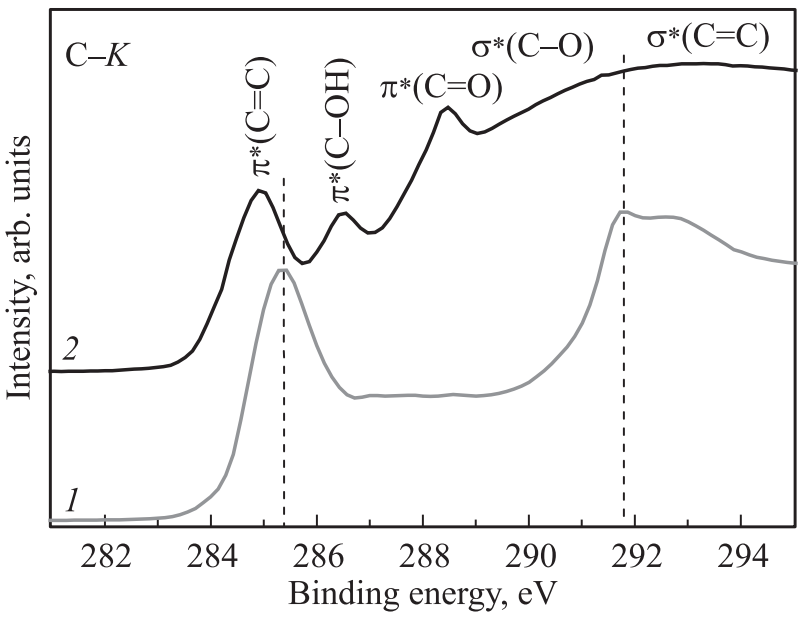

Рис. 5. XANES-спектры углерода (C-K края поглощения) исходных (1) и облученных N-MУНТ (2).

щения К-края углерода отражает переходы электронов с отстовного C $1 s$ на незанятые C $2 s, 2 p$-состояния в зоне проводимости [27]. В спектре исходных N-МУНТ (рис. 5, кривая 1) наблюдается интенсивный и узкий $\pi^{*}(\mathrm{C}=\mathrm{C})$ резонанс на энергии фотонов $285.3 \mathrm{eV}$, а также $\sigma(\mathrm{C}=\mathrm{C})$ резонанс, обладающий двумя локальными максимумами на энергии фотонов 291.7 и $292.8 \mathrm{eV}$. Это свидетельствует о достаточно высокой степени графитизации стенок исходных N-MУНТ.

B XANES-спектре облученных N-MУНT (рис. 5, кривая 2) наблюдаются снижение интенсивности $\pi^{*}(\mathrm{C}=\mathrm{C})$ резонанса и сдвиг его максимума в низкоэнергетическую область на энергию фотонов $\sim 284.9 \mathrm{eV}$. Кроме этого, фиксируется снижение тонкой структуры $\sigma^{*}(\mathrm{C}=\mathrm{C})$ резонанса и наличие дополнительных состояний на энергиях фотонов $\sim 286.4 \mathrm{eV}, \sim 288.5 \mathrm{eV}, \sim 290.5 \mathrm{eV}$, отвечающих $\pi^{*}(\mathrm{C}-\mathrm{OH}), \pi^{*}(\mathrm{C}=\mathrm{O}), \sigma^{*}(\mathrm{C}-\mathrm{O})$ состояниям углерода в составе углерод-кислородных химических связей соответственно [13,28,29]. Указанные особенности спектра свидетельствуют о значительном увеличении дефектности кристаллической структуры и окислении углерода в стенках N-МУНТ. Высокая интенсивность максимумов $\pi^{*}(\mathrm{C}-\mathrm{OH})$ и $\pi^{*}(\mathrm{C}=\mathrm{O})$, отвечающих углероду в составе фенольных/ гидроксильных групп и карбонильных/карбоксильных групп, в XANES-спектре углерода облученных N-MУНТ обусловлена окислением 2-координированных атомов углерода в составе вакансионных кластеров, формируемых в процессе облучения углеродных нанотрубок при последующем контакте с атмосферой. При этом высокая интенсивность сигнала в диапазоне энергий фотонов 289-290.5 eV при отсутствии локальных особенностей, позволяет предположить наличие в стенках углеродных нанотрубок углерода в составе различных $\sigma(\mathrm{C}-\mathrm{O})$ связей, таких как: $\mathrm{C}-\mathrm{O}$, $\mathrm{C}-\mathrm{O}-\mathrm{C}, \mathrm{O}-\mathrm{C}-\mathrm{O}, \mathrm{CO}_{3}[13,29]$. Формирование данных связей на поверхности облученных N-МУНТ приводит к уменышению количества неспаренных электронов уг- 
лерода, что проявляется в снижении плотности занятых состояний вблизи уровня Ферми, наблюдаемом в РФЭ-спектре валентной зоны (рис. 4) и положительному сдвигу линии С $1 s$ (рис. 2).

\section{4. Заключение}

С использованием методов РФЭС и XANES проведен детальный анализ структуры и химического состояния $\mathrm{N}-\mathrm{MУНТ,} \mathrm{облученных} \mathrm{ионами} \mathrm{Ar}^{+}$с энергией $5 \mathrm{keV}$. Полученные результаты показали, что облучение приводит к увеличению степени дефектности структуры $\mathrm{N}-\mathrm{MУНТ} \mathrm{и} \mathrm{окислению} \mathrm{углерода} \mathrm{с} \mathrm{образованием} \mathrm{различ-}$ ных кислородсодержащих групп $(\mathrm{C}-\mathrm{OH}, \mathrm{C}=\mathrm{O} / \mathrm{COOH}$, $\left.\mathrm{C}-\mathrm{O}-\mathrm{C} / \mathrm{O}-\mathrm{C}-\mathrm{O}, \mathrm{CO}_{3}\right)$. Наличие углерод-кислородных связей на поверхности углеродных нанотрубок связано с формированием радиационных дефектов, в том числе 2-координированных атомов углерода, обусловленных вакансиями и вакансионными кластерами в стенках N-МУНТ. Было показано, что увеличение дефектности структуры и окисление стенок углеродных нанотрубок приводит к снижению плотности занятых состояний вблизи уровня Ферми и положительному сдвигу остовной линии углерода. Это дает основание предположить, что дефекты, формируемые в структуре стенок N-MУНТ в результате облучения, являются дефектами $p$-типа. При этом увеличение в результате облучения доли атомов азота в замещающей конфигурации, которые являются донорами, не приводит к повышению плотности занятных состояний вблизи уровня Ферми на фоне увеличения дефектности, окисления углерода и понижения общей концентрации азота.

Таким образом, полученные результаты показывают, что облучение N-MУНТ ионами аргона позволяет эффективно функцианализировать их поверхность. В частности, формирование в результате облучения гидроксильных, эпоксидных, эфирных и карбонатных групп может повышать вероятность закрепления на поверхности МУНТ наночастиц металлов и нестехиометрических оксидов металлов.

Авторы выражают благодарность Ю.А. Стенькину за подготовку образцов для исследований, а также администрации российско-германского канала синхротронного накопителя BESSY II (Берлин, Германия).

\section{Список литературы}

[1] П. Харрис. Углеродные нано-трубки. Синтез, свойства и применение. ОФСЕТ-ТМ, Новосибирск (2016). 220 с.

[2] S. van Dommele, A. Romero-Izquirdo, R. Brydson, K.P. de Jong, J.H. Bitter. Carbon 46, 138 (2008).

[3] S. Mallakpour, S. Soltanian. RSC Adv. 6, 109916 (2016).

[4] A.G. Osorio, I.C.L. Silveira, V.L. Bueno, C.P. Bergmann. Appl. Surf. Sci. 255, 2485 (2008).
[5] V.T. Le, C.L. Ngo, Q.T. Le, T.T. Ngo, D.N. Nguyen, M.T. Vu. Adv. Nature Sci.: Nanosci. Nanotechnol. 4, 035017 (2013).

[6] Y. Zhang, L. Chen, Z. Xu, Y. Li, M. Shan, L. Liu, Q. Guo, G. Chen, Z. Wang, C. Wang. Int. J. Mater. Product Technology 45, 1 (2012).

[7] A. Ishaq, A.R. Sobia, L. Yan. J. Exp. Nanosci. 5, 213 (2010).

[8] A. Ishaq, Z. Ni, L. Yan, J. Gong, D. Zhu. Radiat. Phys. Chem. 79, 687 (2010).

[9] S. Tanuma, C.J. Powell, D.R. Penn. Surf. Interface Anal. 43, 689 (2011)

[10] N. Isomura, T. Murai, T. Nomoto, Y. Kimoto. J. Synchrotron Rad. 24, 1 (2017).

[11] M. Sun, G. Wang, X. Li, C. Li. J. Power Sources 245, 436 (2014).

[12] Y.V. Fedoseeva, L.G. Bulusheva, A.V. Okotrub, M.A. Kanygin, D.V. Gorodetskiy, I.P. Asanov, D.V. Vyalikh, A.P. Puzyr, V.S. Bondar. Scientific Rep. 5, 9379 (2015).

[13] X. Zhang, J. Zhou, H. Song, X. Chen, Yu.V. Fedoseeva, A.V. Okotrub, L.G. Bulusheva. ACS Appl. Mater. Interfaces 6, 17236 (2014).

[14] C.K. Chua, M. Pumera. J. Mater. Chem. 22, 23227 (2012).

[15] G. Yang, B. Kim, K. Kim, J.W. Han, J. Kim. RSC Adv. 5, 31861 (2015).

[16] A. Barinov, O.B. Malcioglu, S. Fabris, T. Sun, L. Gregoratti, M. Dalmiglio, M. Kiskinova. J. Phys. Chem. C 113, 9009 (2009).

[17] T. Susi, M. Kaukonen, P. Havu, M.P. Ljungberg, P. Ayala, E.I. Kauppinen. Beilstein J. Nanotechnol. 5, 121 (2014).

[18] N.A. Davletkildeev, D.V. Stetsko, V.V. Bolotov, Y.A. Stenkin, P.M. Korusenko, S.N. Nesov. Mater. Lett. 161, 534 (2015).

[19] P.M. Korusenko, V.V. Bolotov, S.N. Nesov, S.N. Povoroznyuk, I.P. Khailov. Nucl. Instrum. Meth. B 358, 131 (2015).

[20] K. Fujisawa, T. Tojo, H. Muramatsu, A.L. Elıas, S.M. VegaDiaz, F. Tristan-Lopez, J.H. Kim, T. Hayashi, Y.A. Kim, M. Endo, M. Terrones. Nanoscale 3, 4359 (2011).

[21] D. Usachov, O. Vilkov, A. Gr€uneis, D. Haberer, A. Fedorov, V.K. Adamchuk, A.B. Preobrajenski, P. Dudin, A. Barinov, M. Oehzelt, C. Laubschat, D.V. Vyalikh. Nano Lett. 11, 5401 (2011).

[22] V.V. Bolotov, P.M. Korusenko, S.N. Nesov, S.N. Povoroznyuk, E.V. Knyazev. Nucl. Instrum. Meth. B 337, 1 (2014).

[23] A. Ganguly, S. Sharma, P. Papakonstantinou, J. Hamilton. J. Phys. Chem. C 115, 17009 (2011).

[24] В.В. Болотов, П.М. Корусенко, С.Н. Несов, С.Н. Поворознюк. ФТТ 56, 802 (2014).

[25] Н.А. Давлеткильдеев, Д.В. Соколов, В.В. Болотов, И.А. Лобов. ПЖТФ 43, 47 (2017).

[26] L.G. Bulusheva, Yu.V. Fedoseeva, A.G. Kurenya, D.V. Vyalikh, A.V. Okotrub. J. Phys. Chem. C 119, 25898 (2015).

[27] В.В. Болотов, С.Н. Несов, П.М. Корусенко, С.Н. Поворознюк. ФТТ 56, 1834 (2014).

[28] Yu.V. Fedoseeva, A.V. Okotrub, L.G. Bulusheva, E.A. Maksimovskiy, B.V. Senkovskiy, Yu.M. Borzdov, Yu.N. Palyanov. Diam. Relat. Mater. 70, 46 (2016).

[29] С.Н. Несов, В.В. Болотов, П.М. Корусенко, С.Н. Поворознюк, О.Ю. Вилков. ФТТ 58, 966 (2016). 